\title{
Parental vulnerability
}

\author{
Mianna Lotz
}

Department of Philosophy, Macquarie University, Sydney, Australia

Mianna.Lotz@mq.edu.au

DOI: http://dx.doi.org/10.5324/eip.v11i1.2246

(cc)BY
Attribution 4.0 International License, which permits unrestricted use, distribution, and
reproduction in any medium, provided the original author and source are credited.

Increasing philosophical attention has recently focused on questions of the nature of vulnerability, and of the implications of recognizing and responding to vulnerability in human agents and subjects. Within that field of interest, explorations and analyses of the specific vulnerability of children have raised many interesting questions regarding the nature of childhood and the vulnerability-responsive obligations of parents. By contrast, there has been no philosophical recognition or discussion of parental vulnerability within the parent-child relationship. In this paper I seek to address that theoretical gap, exploring the distinct ways in which parents are vulnerable qua parents, as well as some of the normative implications that follow from a recognition of that vulnerability. These implications include claims of a vulnerability-based foundation for extensive parental authority over children, and the significant role of expanded social structures and mechanisms to more adequately support the parenting of our children.

Keywords: Parenting, vulnerability, cildren, childhood, ethics

My children cause me the most exquisite suffering of which I have any experience. It is the suffering of ambivalence: the murderous alternation between bitter resentment and raw-edged nerves, and blissful gratification and tenderness.

Adrienne Rich, 1976, 21.

\section{Introduction}

Philosophical analysis of the family has burgeoned in recent decades. The grounds and rights of parenthood and procreation, the authority, entitlements and obligations of parents, the moral value of the family, the interests and rights of children, the nature of childhood - a substantial body of philosophical work has clarified, deepened and enriched our understanding of these and so many other aspects of the family and the relationships within it, and has opened fertile new grounds for philosophical investigation. With heightened interest in the concept of vulnerability in recent years, one new area of focus has been the child's distinct vulnerability, regarded by some to be amongst - if not singularly - the most significant of the conditions and properties of childhood. ${ }^{1}$

There is by contrast a notable lack of philosophical consideration of parental vulnerability, in spite of what I will suggest is its salience and significance in the 
parenting role and experience. ${ }^{2}$ The principal task of this paper is to address that philosophical lacuna. Having elsewhere explored the child's distinctive vulnerability within the parent-child relationship, I want to focus here on examining how vulnerability colours the parent-child relationship specifically for the parent, and to consider whether any significant philosophical implications follow from a greater acknowledgment of parental vulnerability specifically, including for conceptions of parental authority.

I will begin with a brief review of children's vulnerability and of the philosophical foundations of parental obligations responsive to it. I then turn to the question of parental vulnerability, drawing on empirical research to clarify its forms and bringing into focus dimensions that are under-acknowledged in analyses of the parent-child relationship. I believe that a consideration of the ways in which parents are distinctly vulnerable will yield a richer and more complete account of the ethical contours of the parent-child relationship. The final section of the paper considers the philosophical implications of acknowledging parental vulnerability, including the question of whether it offers a sound basis for a new argument for extended parental authority.

\section{The child's vulnerability: A brief review}

Conceptually, to be vulnerable is to be susceptible to harm, where harm is broadly construed as the setting back of one's welfare or significant material or psychological interests (Goodin 1985; Feinberg 1987). ${ }^{3}$ What can be said specifically of the child's vulnerability? As I have discussed elsewhere (Lotz 2014a, 2014b, 2016 and forthcoming), the distinctive vulnerability of children qua children arises from their dependency on caregivers as well as from their temporary lack of the full suite of capacities that would mitigate that dependency. The child is in a condition of what Kittay (1999) referred to as 'inevitable dependency' on her caregivers, both for survival and flourishing, a dependency that is physical, emotional and economic.

Children's dependency-based vulnerability is therefore inherent; it is ineliminable from the life course and history of every person. It is also importantly relational, as Goodin influentially highlighted. While a child is vulnerable in a fairly general sense - being largely "defenseless" (Ben-Porath 2003: 135), lacking the resources needed for flourishing and unable to care for herself or pursue her own conception of the good life - it is the dependency-based dimension of a child's vulnerability that is particularly morally significant for vulnerability theorists like Goodin. ${ }^{4}$ Indeed he claims:

Vulnerability implies that there is some agent (actual or metaphorical) capable of exercising some effective choice...over whether to cause or to avert the threatened harm...The implication that an agent exists, in turn, implies that "vulnerability" is essentially a relational notion. (1985: 112, emphasis added).

For Goodin, vulnerability provides the key foundation for a robust theory of moral responsibility: to identify myself as vulnerable to you is to pick you out as having special moral responsibilities towards me - namely to protect my relevant significant interests. Moreover, vulnerabilities and the responsibilities that arise from them are not just relational but also relative: the greater the control you have over outcomes that affect my interests, and the more heavily my interests are at 
stake in the outcomes that you control, the greater is my vulnerability to you (Goodin 1985: 118). ${ }^{5}$ This highlights a critically important feature of the parentchild relationship: namely, its asymmetry and inequality. Children are, as BenPorath puts it, "dependent on the will of people stronger in years, knowledge and physical power" $(2003,135)$. They are, as Brighouse and Swift (2006: 92) state:

...vulnerable to the decisions and choice making of their primary caregivers and, initially, wholly dependent on them for their well-being. Parents have the power of life or death over their children, and this is not, at least when the child is young, reciprocated.

Thus the child's dependency on her caregivers entails that the parent-child relationship embodies an inherent asymmetry and what Ben-Porath called “immanent" inequality (2003: 127).

Importantly, not all forms of relational vulnerability are morally problematic. But Goodin (1985: 195) argues that where a relationship is based upon one party's vital need for something that is necessary to their flourishing and that the other party has unique and discretional capacity to supply, then it is a relationship of objectionable inequality and indeed monopolization. I (and others, see also Gheaus: 2011) have discussed elsewhere the implications of conceiving the child's relational vulnerability to her parent to be morally objectionable, and I have argued that to an extent not yet adequately appreciated, the child's vulnerability does fulfil the key conditions Goodin outlines for what he terms exploitability within a dependency relationship. ${ }^{6}$ To recap: children are relationally vulnerable to their parent(s) in virtue of having significant needs that are uniquely their parent's discretional ability to meet. Two further distinguishing and asymmetric features of the child's relational vulnerability to her parent are that for the child, the relationship is both involuntarily entered into, and preclusive of voluntary exit (at least while the child is young). In intentional parenthood these features further contribute to the morally problematic nature of the parent-child relationship. ${ }^{7}$ I will not review those arguments further here, but instead turn now to consider the presently philosophically unexplored question of parental vulnerability, including the extent to which Goodin's framework applies to the parent within the parent-child relationship.

\section{Parental vulnerability}

That parents are vulnerable qua parents is in some respects actually implicit within philosophical discussion that acknowledges the highly symbiotic nature of the parent-child relationship; yet the entwinement of parent and child is typically depicted only positively, usually in the course of elucidating the parent-centred value and goods of parenting. For example, Thomas Murray (1996: 62) notes "the immense stake parents and children have in each other's flourishing", but in my view glosses the parental side of that mutual involvement as overly positive when he says that "by doing what is loving for their children, parents experience profound satisfaction and develop virtues that promote their own flourishing as well". Likewise, in the course of their important refocusing of attention on parents' interests in parenting (and defending a dual account of parent-child interests as the basis for limited parental rights) Brighouse and Swift (2006) note that "...it is so hard to prise apart the lives of parents from the lives of children while they are being 
raised" (2006: 83), but their emphasis is on the "deep and authentic attachments between parents and children" that they claim are "vital for the well-being of both parties" (2006: 89-90) and a core part of the "important and distinctive contribution [of parenting] to the flourishing of the adults involved" (2006: 98). ${ }^{8}$

To be fair, Brighouse and Swift do refer to the "challenge" (2006: 96) and "moral burden" (2006: 94) of parenting; indeed they suggest that there are some persons "whose lives might actually be diminished by being a parent" (2006: 99). However, these acknowledgements do not capture the kinds of parental vulnerabilities that I am interested in highlighting in this paper. First, at least some of the kinds of vulnerabilities that interest me are much more generalized and potentially ineradicable than those challenges referred to by Brighouse and Swift. They are not, that is, challenges affecting only some people who, for whatever individual reason, are ill suited to parenthood. Second, what Brighouse and Swift refer to as the 'burden' here is that of parents having to withhold some emotional responses from their child, in order to appropriately meet their obligations towards them; specifically they talk of a parent's inability to be wholly spontaneous and intimate with their children, even though their children are unconditionally spontaneous and intimate with them; and of the need to often suppress disappointment, frustration and other negative reactions to their child (2006: 93-94). Again, while I agree that these do constitute parental challenges, these are also not the kinds of vulnerabilities that I want to draw attention to. I am not suggesting that Brighouse and Swift are disinterested in or unaware of the perils and pitfalls of deep intimacy and entwinement in parent-child relationships; their express objective is rather to defend the goods of parenting as a legitimate foundation for a concept of parental rights. But the widespread lack of acknowledgement that parent-child intimacy and entwinement is not unequivocally positive or a guaranteed contributor to flourishing, calls for some correction.

An important qualification is in order before we progress to an analysis of parental vulnerability. The child's vulnerability is sometimes presented as centrally tied to the interest people have in being a parent. Indeed, on certain accounts of the goods of parenting for parents, the vulnerability of the child seems troublingly necessary for the realization of those goods. ${ }^{9}$ But consideration of a parental interest in shaping one's child and inculcating one's own values in them, for example, indicates the considerable scope there is for a form of parental domination over children that I have argued is illegitimate (Lotz, 2014a). Nothing I say about parental vulnerability in what follows is intended to discount the significant power that parents have in relation to their children, nor to minimize in any way the vulnerability of children. My purpose is only to suggest that the nature and role of vulnerability within parent-child relationships is a great deal more complicated than existing philosophical discussions have acknowledged to date. The omission of parental vulnerability from analyses of relational vulnerability - including by Goodin - is what this paper seeks to correct.

In contrast with the paucity of philosophical discussion, a vast range of empirical psychological and sociological research examines the experiences and impacts of parenthood for women, men, and their relationships (marital and non-marital, same-sex and heterosexual). However, consensus regarding overall or net impact positive or negative - remains elusive. This is to some extent a function of the many moderating demographic variables that appear to influence parenting experience, 
including gender, economic conditions, social support, marital status, division of domestic labour, and child care availability. ${ }^{10}$ From their meta-analysis of empirical studies Nomaguchi and Milkie (2003: 356) conclude that, considered in their totality, the findings are largely inconclusive and significantly inconsistent: analyses yield both positive and negative findings regarding parenthood. Positive findings include enhanced life satisfaction, sense of purpose and general mental health of parents versus non-parents, while negative ones have to do with the overall greater 'costs' and burdens than benefits of parenthood.

In the latter category are studies that indicate a significant decline in individual and/or marital well-being among parents. ${ }^{11}$ McLanahan and Adams (1987: 248) claim that their meta-review yields the general finding that " $\mathrm{t}]$ he presence of children appears to be associated with lower levels of happiness and satisfaction and with higher levels of psychological distress for both women and men". Powdthavee (2008) refers to numerous analyses of European and American data sets of evidence that on average parents report statistically lower levels of happiness, life satisfaction, marital satisfaction and mental well-being compared with non-parents. ${ }^{12}$ Indeed there is also evidence that the impacts associated with parenthood are not limited to the period during which children are physically and economically dependent, with at least one study suggesting that older parents whose children have left home report the same or slightly less happiness than non-parents of similar age and status (Glenn and McLanahan, 1981). Finally, a series of studies have reported that many parents - and in particular women - find that the transition to parenthood itself brings considerable unexpected impacts and, in many cases, psycho-emotional (as well as physical) shock. ${ }^{13}$

While it is widely agreed that socio-demographic factors - and in particular, increased strain on financial and family resources - play a significant causal role in parents' decreased satisfaction and increased stress, a more recently reported and significant data analysis has suggested that such factors cannot wholly explain the finding that having children is negatively related to subjective well-being (Stanca 2012). ${ }^{14}$ Acknowledging the subjective nature of self-report studies, Stanca notes the difficulty posed by possible omitted variable bias, including individual psychological factors such as optimism and pessimism bias. Nevertheless he concludes that "the net effect of having children is negative and large even when controlling for unobserved individual characteristics" (Stanca 2012: 748). For our philosophical purposes, however, it does not so much matter why parents report lower well-being than non-parents, only that it appears that they do so.

Other studies, in contrast, suggest that the experience of parenthood, while stressful, is nevertheless on balance more satisfying and gratifying than difficult. ${ }^{15}$ Bird (1997) notes that some studies indicate parents are better off than non-parents in terms of mental health. ${ }^{16}$ One recent study found that parents report higher levels of both momentary and global well-being, fewer depressive symptoms, and higher levels of life satisfaction, positive affect, and sense of meaning in life, than do nonparents (Nelson and others, 2013).

Yet further studies cited by Nomaguchi and Milkie (2003) claim to have found consistent evidence of no association between having children and either happiness or psychological distress, with parents and non-parents on average reporting the same levels of life satisfaction. ${ }^{17}$ One finding that is consistently established, however, is that the strains and rewards of parenting vary significantly according to 
marital and gender status. In particular, several studies confirm that single mothers fare worse across all relevant measures, both psycho-emotional and socio-economic (McLanahan \& Adams, 1983: 248). ${ }^{18}$ Some theorists have even argued that gender and marital status so significantly moderate how parenthood affects adults' lives that "it may not be meaningful to discuss parents as a social category" (Nomaguchi and Milkie, 2003: 357).

The volume and complexity of parenting impact studies means that a great deal more remains to be said about the multiple impacts of parenting on life satisfaction, employment, income and economic status, mental health, and marital satisfaction. It lies well beyond the scope of this paper to explore the complexities of those studies and analyses more extensively. ${ }^{19}$ What can be surmised from these studies, however - and this is the key point for my purposes - is that whatever the net impact of parenting on parents' lives, the existence of some level of negative impact renders a net estimation extremely difficult; and that is sufficient for a claim that the parent-child relationship is one in which parents, and not merely children, are rendered vulnerable. Even setting aside the observed impacts of having children, one must consider the nature of intimacy itself. Notwithstanding its power and scope for promoting the flourishing of parents and children, intimacy is always perilous; it exposes us to emotions that we may not be prepared for and may not welcome, and it does so unavoidably. We cannot experience intimacy with another person - child or adult - without being thereby made vulnerable. And the deeper the intimacy, the more profound the vulnerability. In the parent-child case, the vulnerability may be asymmetric - indeed I believe it always will be, given the distinct properties and capacities of children and the social conditions of childhood, as compared with those of adults and adulthood. But while it may be somewhat mitigated, the power asymmetry between parents and children does not cancel out parental vulnerability. Nor does it diminish its moral significance for a comprehensive understanding of the ethical contours of the parent-child relationship.

At this point we can consider in a little more detail some of the more specific risks of harm to which parents are distinctly vulnerable, before we move to the philosophical implications. First, in the most extreme cases parents can be victims of parent abuse. Classified as a hidden form of domestic violence, parent abuse can be defined as any act committed by a teen or young adult that is intended to cause physical, emotional or financial damage as a means to gain power and control over a parent, and/or any behaviour that is deliberately harmful to and/or causes fear in the parent..$^{20}$ A substantially under-reported and under-researched phenomenon, parent abuse has only recently gained public recognition, and remains significantly underinvestigated and under-reported. Despite widespread lack of official data collection (including by police) it is estimated to be increasing in prevalence (Bobic, 2004). A recent study of police data in Greater London, for example, revealed 1,892 reported cases of violence committed by 13-19 year olds against their parents over a 12month period from 2009-2010 (Condry \& Miles, 2012). Parents interviewed as part of that study reported strong feelings of guilt, shame and stigma, suggesting that actual rates of parent abuse are likely to be substantially higher than reported. An early study by Straus, Gelles \& Steinmetz (1980) produced estimates of one in five children striking a parent each year, with one in ten using a method of violence carrying a high risk of parental injury (Evans \& Warrant-Sohlberg, 1988). Bobic 
(2004: 3) also reports figures on the prevalence of adolescent violence from the late 1980 s and early 1990s, which estimates a prevalence in the United States of 7-18\% in two-parent households and as high as $29 \%$ in one-parent households. The (undifferentiated) prevalence reported in Canada was 10\%. Bobic (2004: 3) notes, however, that a more recent (though small) Australian study reported rates of adolescent-on-parent violence in two-parent households to be similar to those in one-parent households.

It is undeniable that as adults, parents have substantially more resources and capacities at their disposal with which to respond to such violence and abuse than do children suffering child abuse. However, it should not be overlooked that opportunities to escape an abusive situation vary greatly depending on factors such as marital status and wider family and social support. Relinquishing an emotional and care relationship with an abusive child is not an option that is realistically open to all - or even most - parents who are victims of parent abuse. This is an important point in relation to classical vulnerability theory, and I will return to it in Section III.

An important point for my purposes, however, is that beyond possible abuse within relationships that are in extremis, even flourishing parent-child relationships render parents susceptible to harm arising from emotional hurt as a consequence of the deeds and words of their children. Children can say and do hurtful things to parents, most commonly as a result of episodic anger and frustration at being hindered from expressing their desires and executing their wills, or at having the authority of others in some way imposed upon them. A parent's task in such situations is, as Brighouse and Swift suggest, to suppress spontaneous responses to such behaviour and to rationalize it appropriately - that is, as the largely unwitting, uncontrolled and excusable expression of a child's emotions, and sometimes deliberate opposition as they test out adult boundaries in a bid to discover the appropriate limits to self-expression and self-assertion. An emotionally healthy, well-supported parent will not be significantly adversely affected as a result of such emotional hurt. But it would be wrong to suppose that they do not suffer, and in some cases they are harmed. ${ }^{21}$ Given that challenging behaviour is widely regarded as an important and necessary stage of development in a child's healthy detachment from her parents, some degree of emotional suffering seems a persistent and ineradicable feature of the parent-child relationship to which parents are distinctly vulnerable.

A further and equally important way in which parents are vulnerable in the parent-child relationship, is connected more to parents' psycho-emotional responses to parenting itself, rather than directly to any specific conduct of children, as was the case in the previous examples. These include responses such as anxiety, ambivalence, regret, guilt, and over-engagement. The risk of parents experiencing these feelings should be understood as largely independent of child characteristics and behaviours, though parents of children with special challenges are likely to be at greater risk of developing these kinds of psycho-emotional responses. Of these, one of the most commonly recurring experiences reported in empirical studies is what is characterized in psychoanalytic, feminist and sociological discourse as the phenomenology of ambivalence (most commonly maternal ambivalence). One prominent ambivalence researcher, Rozsika Parker, defines it as "a dynamic coexistence of the experience of love and hatred" that she says constitutes the "unacceptable face of motherhood" (14). Parker emphasizes the non-static nature of 
ambivalence, pointing out that the "dialectical tensions", as Arendell (2000) calls them, occur on a moment-by-moment basis and throughout different stages in a child's development. And in her particularly evocative depiction of the phenomenon, novelist Rachel Cusk (2001: 80-81) writes:

My compassion, my generalized human pity, has become concentrated into a single wound, a dark sore of knowing and of the ability to inflict...it is not to love but to its lack that I am suddenly alive... I have merely become more afraid of love's limits, and more certain that they exist.

Many scholars point to the extent to which ambivalent feelings are suppressed by mothers, in particular, as a result of what is claimed to be an 'ideology of mothering' and a 'Good Mother' paradigm. In light of strong societal valorization, the admission of negative feelings towards one's child, and towards the parenting experience in general, is likely to be stigmatized and wrongly regarded as evidence of parental failure and lack of love. Parents therefore commonly suppress and hide these feelings. ${ }^{22}$ Within a culture in which motherhood is idealized and romanticized to this extent, experiences of ambivalence in turn give rise to (in some cases very intense) feelings of guilt and shame - two further emotional risks to which parents are vulnerable.

Additionally, the inevitable mistakes and minor instances of neglect that occur in daily parenting are further sources of episodic feelings of guilt and inadequacy for many, if not all, parents. In relation to ambivalence, however, we see that it is not just routine failures to pay sufficient attention or be sufficiently patient towards one's child that can cause guilt. Perceived internal emotional 'failures' - to fully and consistently experience parental joy and unwavering positive affect towards one's child - can also cause parents to feel deeply inadequate and guilty.

Distinct from the dynamic fluctuations of episodic ambivalence, some parents experience more stable, generalized and persistent feelings of regret about having had children. Needless to say, significant disclosure obstacles of the kind referred to earlier - especially perceived stigmatization risk - confound evidence gathering in relation to this phenomenon. But while limited, some such evidence does exist. It suggests that maternal regret in particular crosses class and other sociodemographic categories - including age and stage of parenthood - and is predominantly bound up with and contributed to by feelings of loss: specifically, loss of sense of self and identity, freedom and control, time and opportunity. ${ }^{23}$

Finally, parents are obviously also vulnerable to experiencing considerable anxiety in relation to various aspects of their child's development and well-being. While a significant degree of concern for one's child is obviously appropriate and healthy, more severe manifestations of parental anxiety may result from what theorists describe as a 'self-effacing' and self-abnegating mode of empathic engagement, in which the parent becomes overly bound up with and invested in the child's feelings, perceptions and interpretations (Carse, 2005; Halpern, 2001; Piper, 1991). The deep intimacy of the parent-child relationship, combined with the child's dependency and vulnerability to the parent, suggests that this kind of emotional over-involvement, which goes beyond appropriate empathic attunement to one's child, is a risk to which parents are distinctly vulnerable. ${ }^{24}$

To the above consideration of the kinds of vulnerability specifically (though not uniquely) associated with parenting can be added vulnerability to fear, loss, grief, anger, exhaustion, depression, diminished sense of self-efficacy, financial difficulty, 
marital disruption, and loss of opportunity (career, travel, sporting, etc). The question is, what, if anything, follows philosophically from an acknowledgement of parental vulnerability? What is the philosophical significance, and what are the implications, of drawing a more accurate - and more complete - picture of the parent-child relationship by acknowledging the vulnerability of the parent within that relationship? I turn to these questions now.

\section{Philosophical implications of parental vulnerability}

The first question I want to consider concerns the implications from an appropriate acknowledgement of parental vulnerability, specifically for a Goodin-style analysis of the dependency-based vulnerability inherent in the parent-child relationship. The second question concerns whether there are any implications that follow for an account of the alleged specific entitlements of parents, in particular in relation to parental authority claims. I close with consideration of the relevance of the wider social structures and contexts within which parent-child relationships typically develop for properly responding to the morally significant reality of parental vulnerability.

Recall that for Goodin, relational vulnerability within a dependency relationship becomes increasingly morally problematic to the extent that one person within the relationship has vital needs, necessary for their flourishing, that can only be met by the other; and they are unable to freely and voluntarily exit the relationship and have those needs readily met by someone else. Now, it would clearly not be plausible to depict the child as the superordinate person in the parent-child relationship, nor as having discretionary control over what the parent needs from them. Nevertheless, two combined facts - that the relationship is in key respects (namely, emotionally) non-fungible for the parent, and that the parent does not have ready voluntary exit capacity - mean that the vulnerability of parents within the parent-child relationship is far from morally insignificant, even if it is not sufficient to establish the kind of mutual dependency that for Goodin would mitigate the objectionability of relational vulnerability, namely by moderating its asymmetry and inequality. ${ }^{25} \mathrm{Of}$ course, many of the goods afforded, and needs fulfilled, by a parent-child relationship are not unique to the parent-child relationship, such as intimacy and affection, for example. These more general relationship goods should be set aside here, though. For our analysis of whether parental vulnerability fulfils Goodin's conditions for morally troubling relational vulnerability, we must consider only those needs and goods that are alleged to be unique to parent-child relationships. And in doing so, it is clear to me that even if we must accept that in advance of a parent-child relationship a person's perceived needs for the goods of parenting could in principle be met by parenting any child (and in that weak sense no child is uniquely able to meet a parent's needs); and given moreover that it is contestable whether parenting is necessary, or even reliably conducive, for a flourishing life, that pre-relationship analysis no longer applies once a specific parent-child relationship has come into existence. A starting assumption in the application of that analysis is incorrect. Relational vulnerability is about vulnerability in relation to an actual other, not a future, possible other. Once an adult is in a parental relationship with a child, that child is essential to the realization of parenting goods for the parent, and is uniquely able to meet the parent's specific parenting needs. The relevant object of 
the parent's need is not the commencement of a parent-child relationship but rather the continuation of the existing parent-child relationship. That relationship has become central to a parent's well-being and flourishing, and this remains true even if the relationship has seriously deteriorated, including to the point of removing the child. No parent flourishes when that happens; indeed the loss or removal of a child is one of the greatest of all threats to parental well-being and flourishing, even if the relationship was failing and the removal fully justified. A specific parent-child relationship is non-substitutable by any other such relationship.

To be clear, I am not suggesting that the continuation of the parent-child relationship is of overriding importance and must be achieved at all costs, no matter the harms that might ensue for either child or parent. That is plainly not the case. But this acknowledgement does not preclude recognizing the significant detriment to parental flourishing that is incurred wherever a parent-child relationship is lost. Viewed in that light, the asymmetry of vulnerability in the parent-child relationship is considerably less extreme than may be commonly assumed. Denial of that would run roughshod over the significance of parental needs and the non-trivial nature of the vulnerabilities that arise from them.

Consider now the second question, which concerns whether any normative implications follow from a proper acknowledgment of parental vulnerability, in particular for parental authority claims. ${ }^{26}$ A proposal might be offered as follows. Philosophical arguments defending the paramountcy of a child's interests may have persuaded us that whatever the basis of a parent's interests in extensive and robust authority over their children, those interests are appropriately constrained and outweighed by the more morally significant interests (and perhaps rights) of children. The allocation of extensive parental authority entitlements would inevitably come into conflict with the child's interests, properly understood. However, in recognizing parental vulnerability, we have a new basis for extending greater parental entitlements and authority. Accordingly, for example, a parent's vulnerability entitles them to greater scope for inculcating their own values in their children, and for delimiting their children's access to certain forms of education and lifestyle, than is permitted on the accounts of at least some recent theorists. ${ }^{27}$

On what grounds might a distinctly vulnerability-based parental authority argument be defended? An intimacy-based justification might be offered, namely that the ability to exert greater control over a child's values and the direction of their development, would be likely to bring about greater parent-child similarity and thereby enhanced parent-child attachment and intimacy. This would in turn reduce some of the threats to well-being and flourishing to which we have seen that parents are vulnerable. A defence might alternatively be framed as a compensatory justification, that the allocation of extensive parental authority is warranted (and perhaps even required) in order to compensate parents for taking on a role in which they are made considerably more vulnerable than they otherwise would be. Or it may be framed as a protection-based justification: specifically, given that a person will be made more vulnerable as a result of becoming a parent, she has an interest in having that vulnerability protected against or mitigated wherever possible, and the entitling of greater parental authority will provide such protection and mitigation.

Indeed it is my intuition that whether rationally justifiable or not, vulnerability in fact substantially underpins many bids for greater parental control and authority over children. Such claims are sometimes attributed to a misplaced proprietary 
conception, that is, parents in some sense think they 'own' their children, and feel entitled to significant authority over and in relation to them. However, while I cannot substantiate the claim here, I suspect that it is at least as much a sense of vulnerability that provides the psycho-emotional impetus for many parental control and authority claims. The thinking behind that claim is that greater authority and control will correspond to reduced risk and less vulnerability, perhaps for the child, but more relevantly here, for the parent.

Regardless of the empirical psychological facts as to what motivates such claims, however, we are in search of a rational foundation for this vulnerability-based parental authority argument. Does such a foundation exist? The suggested justifications do not conclusively provide one. Consider first the intimacy-based justification. Intuitively, it may seem a compelling claim that sharing values and interests with ones child will promote intimacy with them, particularly if we are thinking of deep substantive values and significant interests. Nevertheless, many regard the sharing of common activities and a common life as key to and sufficient for building intimacy within the family. ${ }^{28}$ Intimacy forged through shared living does not require similarities of personality, values or interests. Moreover, possession of certain parental traits - such as tolerance, compassion, interest in their children's lives and general open-mindedness - seems much more crucial for the development of parent-child intimacy than does similarity of values and interests. It is also easy to imagine parental efforts at securing similarity instead resulting in a child's resistance to what they perceive to be excessive parental pressure, and that resistance, rather than any dissimilarity per se, would inhibit intimacy rather than support it. While it may be possible to develop a stronger defence of the necessity of similarity for intimacy, I am not aware of one at this point.

In terms of the compensation justification, we should start by noting that compensation is only payable where a person or party becomes worse off - injured or harmed - or has their interests set back in some way. Where the affected party voluntarily worsens their condition, compensation is not usually regarded as due. ${ }^{29}$ In addition, an underpinning assumption about compensation is that it can, in some sense, ameliorate or mitigate injury, harm, setback, and suffering. I cannot hope to settle the question here of whether any kind of compensation could ever ameliorate or mitigate vulnerability, but it is not clear that parental vulnerability ought to be ameliorated or mitigated, since it has not been established that such vulnerability is, on balance, a bad thing. Indeed, it may be more plausible to regard parental vulnerability as tolerable and even good insofar as it is intrinsically tied to the goods of intimacy and the kind of care and concern that is ideal for the parentchild relationship. As I have explained, my argument is solely to defend recognition of parental vulnerability, and as such I do not take a stand on questions of the overall good or harm of parenting. Finally it must be remembered that to be vulnerable is not necessarily to experience injury, harm, setback or suffering, but only to be at risk of experiencing those. It is only actually occurring injury, harm, setback or suffering that could be the subject of a compensation justification, and not vulnerability itself.

Finally, what about the protection-based justification for extensive parental authority? Could extended parental authority and control reduce parental vulnerability by reducing the risks of psychopathologies such as anxiety and depression? Countering this justification is an overwhelming volume of empirical 
research showing that attempting anxiety reduction via increased effortful control over external conditions and persons, is at best ineffective and at worst counterproductive. Numerous studies - too many to cite here - support alternative interventions and responses that involve simply focusing attention and observing one's internal experience rather than seeking to change external conditions. Readily available examples can be found in the work of Jon Kabat-Zinn and colleagues in relation to the use of mindfulness-based therapeutic techniques and interventions for anxiety and stress reduction, and - relevant for our discussion here parenting. ${ }^{30}$ The capacity to cope with feelings of vulnerability appears to be worsened, not improved, by attempts to aversively control external factors that make one feel vulnerable. ${ }^{31}$

This outcome may seem counterintuitive, and indeed it may not be generalizable to all cases of vulnerability and all types of control. But as indicated, psychotherapeutic evidence points to the existence of such a vulnerability-control paradox. The contrasting approach, of developing one's capacities to tolerate and endure, rather than to avoid or escape, vulnerability, is more likely to both reduce vulnerability-related anxiety and to maintain the (valuable) intimacy that gives rise to vulnerability in the first place. I suggest therefore that quite apart from the common inefficacy of parental efforts to control or shape their child to more closely align with their own wants and preferences, the parents' sense of vulnerability would likely not thereby be reduced or eliminated, even if such control were achieved. Nor, of course, would their actual vulnerability.

We come then to the final philosophical question for consideration here. What implications follow from recognition of parental vulnerability for the existence and structure of the relationships within which these vulnerabilities arise? I believe that one of the most important implications of an adequate acknowledgement of the nature and extent of parental vulnerability is that it provides a further, powerful consideration against highly insular, private and exclusionary family structures that is, against much of what is currently recognized as the traditional nuclear, dyadic family unit. We already know that the highly private nature - and consequently quite exclusionary and 'closed' structure - of the typical nuclear family can be highly hazardous for children, constituting an enabling condition for undetected child neglect, abuse and domination. ${ }^{32}$ It also constitutes an enabling condition for women's continued gender oppression and subordination, and for domestic abuse of all kinds. Recognition of parental vulnerability provides compelling additional moral grounds to provide strong extra-familial social scaffolding and support for parents, to effectively assist them in maintaining intrafamilial relationships that promote their well-being and flourishing. While too extensive to list comprehensively here, adequate social scaffolding and support include at least the following: prioritization of support networks for parents and families; provision of high quality publicly funded childcare and education; mandatory provisions for carer leave and family-flexible work schedules within all employment contracts; and provision of accessible, affordable educational and therapeutic services for parents.

In addition, proper recognition of parental vulnerability lends further support to already compelling arguments for extending child-rearing responsibilities beyond the nuclear biological family to non-parental care. ${ }^{33}$ Ensuring that interested and appropriate adults outside of the nuclear family are closely involved in the raising of 
children is not just beneficial for children, but can substantially diffuse the challenges and burdens of the parenting role and thereby ameliorate some of the risks and vulnerabilities of parents that I have discussed here. Indeed I would suggest that a dual consideration of child and parent vulnerability gives us very strong cause to question our deeply entrenched norms and commitment to the nuclear family structure itself, and to take seriously the challenge to reconceive our current moral and legal conceptions of the family and the roles and obligations it generates. In this respect, as in so many others, we will see that far from being antagonistic, the vulnerability-related needs and interests of parents and children in fact dovetail when it comes to matters of the ideal structure and socio-material conditions of healthy families.

\section{Conclusion}

My main objective in this paper has to been to establish that there has to date been a problematic lack of philosophical acknowledgement of parental vulnerability within the parent-child relationship. I have sought to explain the nature of parental vulnerability and to examine some of the specific causes and manifestations of it. My goal has not been to suggest that the parent's vulnerability is morally equivalent to or indeed greater than that of the child. Those would not be defensible claims. Yet I think we can hereby establish that there is not the extreme asymmetry of vulnerability between parents and children that might commonly be assumed. The potential threats and challenges to parental well-being and flourishing in the parentchild relationship are far from trivial, even though they are of a different quality and calibre from those faced by children.

I have rejected the idea - albeit in a fairly preliminary fashion - that appropriate acknowledgement of parental vulnerability supplies a new, distinctly vulnerabilitybased argument for extensive parental authority over children. And I have argued that more robust and extensive extra-familial support is supported by a consideration of parental vulnerability as surely as it is by a consideration of child vulnerability. If we needed further grounds on which to embrace non-traditional nuclear family structures, a consideration of parental vulnerability surely supplies us with one such additional reason.

\section{Notes}

${ }^{1}$ A claim made for example by Ben-Porath (2003): 127.

${ }^{2}$ By 'parent' I intend 'social parent' rather than the more narrow categories of either 'biological parent' or 'legal parent'. My account is also intended to be neutral with respect to the question of how many parents a child can have, and assumes a rolebased and 'contribution' account of what makes a parent and what grounds parenting rights as well as responsibilities. Thus my account aligns with those proposed and defended by Millum $(2008,2010)$ and Hannan \& Vernon (2008).

${ }^{3}$ Goodin's influential book on vulnerability proposed the following as an initial characterization: "[S]omething is 'vulnerable' if it 'may be wounded', either literally or figuratively; it is 'susceptible of injury, no proof against weapon, criticism, etc.'. Essentially, then, the principle of protecting the vulnerable amounts to an injunction to prevent harms from befalling people. Conceptually, "vulnerability" is 
essentially a matter of being under threat of harm; therefore, protecting the vulnerable is primarily a matter of forestalling threatened harms." (1985: 110) As such, Goodin later points out, "the principle of protecting the vulnerable would seem to enjoin more than merely refraining from acting in such a way as to cause others harm". (114)

${ }^{4}$ See also Fineman 2008; Butler 2004; 2009; Turner 2006.

${ }^{5}$ Goodin's 'first principle of individual responsibility' holds that 'if A's interests are vulnerable to B's actions and choices, B has a special responsibility to protect A's interests; the strength of this responsibility depends strictly upon the degree to which B can affect A's interests (1985: 118).

${ }^{6}$ It should be clarified that it is not children's general vulnerability that Goodin regards as morally objectionable; rather, it is the nature and extent of a child's asymmetrical relational dependency on their parent(s) - and hence specifically their exploitability - that constitutes the morally troubling or 'objectionable' aspect of their vulnerability. Thanks to an anonymous reviewer for prompting this clarification.

${ }^{7}$ Not all parenthood is planned, yet where it is not there is, for some at least, the possibility of termination of pregnancy or adoption, a fact that in many instances preserves the entry asymmetry in the relationship. Note also that not all view parent-child asymmetry as unequivocally problematic. Christine Overall (2012), for example, argues that it is precisely the asymmetry within the parent-child relationship that makes possible the "mutually enriching, mutually enhancing love" that exists between parents and children which, for Overall, provides the strongest moral grounds for procreation (2012: 217).

${ }^{8}$ Brighouse and Swift refer here to "the enjoyment of the love (both the child's for oneself and one's own for the child) and the delight in the observations the child makes about the world: the pleasure (and sometimes dismay) of seeing the world from the child's perspective; enjoyment of her satisfaction in her successes, and of being able to console her in her disappointments." (p. 94).

${ }^{9}$ In this vein Hannan and Leland suggest (forthcoming, 21) that the powerful interest of adults in being parents is necessarily connected with the child's vulnerability, such that in the absence of the kinds of features that constitute that vulnerability, “... many [parents] would no longer have an interest in parenting." I agree with Hannan and Leland that if true, this would be morally troubling and we would have good reason to reject it as the basis for any kind of parenthood claim. However, for reasons discussed in future research and unable to be reviewed here, I do not wholly accept this proposal.

${ }^{10}$ It should be noted that there are also documented methodological challenges that confound the research, such as selection effects, recall biases, investment-based rationalizing, dissonance reduction, and beliefs about the desirability of parenting. Such confounders are discussed for example by Eibach \& Mock (2011), Robinson \& Clore (2002), and Nelson and others (2013).

${ }^{11}$ For examples of many such studies see Cast (2004) and Nomaguchi and others (2003). For a more recent study see Stanca (2012).

${ }^{12}$ See also Demo \& Cox (2000) for a review of the impact of new parenthood on marital relationships.

${ }^{13}$ See for example Shelton and Johnson (2006); Newman (2008); Read, Crockett \& Mason (2012). 
${ }^{14}$ Data was analysed based on approximately 225,000 survey observations from 94 countries.

${ }^{15}$ Bird (1997) and Ross and Huber (1985). See also the studies cited in Harriman (1983) and Nelson, Kushlev, English, Dunn \& Lyubomirsky (2013).

${ }^{16}$ See for example Umbersome \& Gove (1989).

${ }^{17}$ See also Powdthavee (2009).

${ }^{18}$ See also findings such as those presented on the website of the National Survey of Families and Households (NSFH), available at http://www.ssc.wisc.edu/nsfh/

${ }^{19}$ Some different philosophical implications arising from the more recent of these studies are also discussed in McTiernan (2015).

${ }^{20}$ For definitional discussions, see for example Romans and others (2001) and Cottrell (2001). Note that pre-teen abuse of parents also occurs. Some studies have claimed that as many as $11 \%$ of abusers may be under the age of 10 years old. See Robinson, Davidson \& Drebot (2004).

${ }^{21}$ Of course as children grow older they typically acquire a more nuanced understanding of their parents' weaknesses and sensitivities, from which they develop a more effective behavioural arsenal (metaphorically speaking) with which they can (intentionally or not) emotionally hurt their parent. Concomitantly the challenge of remaining emotionally unscathed may increase rather than decrease in difficulty for the parent as the child ages.

${ }^{22}$ See for example Quiney (2007).

${ }^{23}$ Including from one qualitative study with 23 mothers in explicitly pro-natalist Israel - see Donath (2015). The women in this study self-selected as parents who regret becoming mothers, so the study yields no indication of prevalence rates of the experience of maternal regret, but does nevertheless provide rich and nuanced accounts of how maternal regret is experienced by these women. All 23 women in the study concluded that from their perspective, the disadvantages of parenthood outweigh the benefits, and in some cases felt that there is "nothing benign about maternal experience" and that on the contrary, "it adds only difficulty and worry" to life (2015: 359).

${ }^{24}$ A point not intended to discount or downplay the negative impacts on the child from this kind of parental over-involvement.

${ }^{25}$ See Goodin (1985: 196ff).

${ }^{26} \mathrm{I}$ here avoid presupposing that it is the allocation of rights that we are talking about. Certainly it is common to regard rights allocation as the means by which to protect and/or promote morally significant interests (indeed I think that that is the most plausible account of the nature and foundation of rights). However, my account here remains uncommitted with respect to notions of rights, focusing instead on claims and entitlements rather than assuming that these must be translated into rights language.

${ }^{27}$ Such as Macleod (2017), Brennan and Macleod (2017), Ramsay (2017), Marples (2017) and myself (2014a).

${ }^{28}$ See for example David Archard's article in Archard and Macleod (2002).

${ }^{29}$ An exception might be where incentivization is at play. If for whatever reason we wished to incentivize adults to enter into parent-child relationships in which they become vulnerable, then we might seek to compensate them in some way (such as by according them greater control rights and authority) as a mechanism by which to induce them to bring those relationships about. But in that case, a compensation 
argument rests upon a prior commitment to procreative value - that is, to the value of establishing parent-child relationships, however that is done. And it is not the establishing of parent-child relationships that we are considering here.

${ }^{30}$ For just two examples see Kabat-Zinn (2003) and Kabat-Zinn and Kabat-Zinn (1997/2014).

31 A wealth of research data also supports claims that excessive parental control contributes to socio-emotional adjustment problems in children, but here I am interested in parental well-being rather than child well-being, and in the failure of parental control to reduce parental anxiety and vulnerability. For a recent discussion of research on parental-control-related child anxiety, see for example Stevens, Bardeen \& Murdock (2015).

${ }^{32}$ It may be that there are cultural variations in the extent of privacy and therefore exclusivity of what I am here referring to as the 'typical nuclear family', perhaps in particular if we compare families in Scandinavia and some other European countries with families in the UK, United States, Canada, New Zealand and Australia (what we might refer to as the Anglo-American model of the typical nuclear family). This is an empirical and sociological matter that I cannot evaluate in this paper; but certainly my comments here can be taken to apply at least to the dominant Anglo-American nuclear family norm. Thanks to an anonymous referee for pointing out the need for this qualification.

${ }^{33}$ See for example Gheaus (2011).

\section{References}

Alstott, A. (2004). No exit: What parents owe their children and society owes parent. Oxford: Oxford University Press.

Archard, D. (1993). Children: Rights and Childhood. London/New York: Routledge. (2002). Children, multiculturalism and education. In Archard, D. and Macleod, C. (Eds.), The Moral and Political Status of Children (pp. 142-159). Oxford: Oxford University Press. https://doi.org/10.1093/0199242682.003. 0008

Arendell, T. (2000). Conceiving and investigating motherhood: The decade's scholarship. Journal of Marriage and the Family 62(4): 1192-1207. https://doi.org/10.1111/j.1741-3737.2000.01192.x

Bird, C. E. (1997). Gender differences in the social and economic burdens of parenting and psychological distress. Journal of Marriage and the Family 59: 809-823. https://doi.org/10.2307/353784

Bobic, N. (2004). Adolescent violence towards parents: Topic paper. Australian Domestic and Family Violence Clearinghouse, available at http://www.adfvc.unsw.edu.au/pdf\%20files/adolescent_violence.pdf Last accessed 12/08/2015.

Ben-Porath, S.R. (2003). Autonomy and vulnerability: On just relations between adults and children. Journal of Philosophy of Education 37(1): 127-145. https://doi.org/10.1111/1467-9752.3701009

Brennan, S. and Macleod, C. (2017). Fundamentally incompetent: Homophobia, religion and the right to parent. In Ahlberg, J. and Cholbi, M. Eds.), Procreation, Parenthood, and Educational Rights: Ethical and Philosophical Issues (pp. 230-245). New York: Routledge. 
Brighouse, A. and Swift, J. (2006). Parent's rights and the value of the family. Ethics 117 (October): 80-108. https://doi.org/10.1111/1467-9752.3701009

Butler, J. (2004). Precarious Life: The Powers of Mourning and Violence. London: Verso.

2009. Frames of War: When is Life Grievable? London: Verso.

Carse, A.L. (2005). The moral contours of empathy. Ethical Theory and Moral Practice 8: 169-195. https://doi.org/10.1111/1467-9752.3701009

Cast, A.D. (2004). Well-being and the transition to parenthood: An identity theory approach. Sociological Perspectives 47(1): 55-78. https://doi.org/10.1111/14679752.3701009

Condry, R. and Miles, C. (2012). Adolescent to parent violence and youth justice in England and Wales. Social Policy and Society 11(2): 241-250. https://doi.org/10.1017/S1474746411000601

Cottrell, B. (2001). Parent Abuse: The Abuse of Parents by their Teenage Children. Ottawa: Health Canada. Available at http://www.hc-sc.gc.ca/nc-cn (Last accessed on March 20, 2017).

Cusk, R. (2001). A Life's Work: On Becoming a Mother. London: Harper Collins.

Demo, D.H. and Cox, M.J. (2000). Families with young children: A review of research in the 1990s. Journal of Marriage and Family 62(4): 876-895. https://doi.org/10.1111/j.1741-3737.2000.00876.x

Donath, O. (2015). Regretting motherhood: A sociopolitical analysis. Signs 40(2): 343-367. https://doi.org/10.1086/678145

Eibach, R. P., \& Mock, S. E. (2011). Idealizing parenthood to rationalize parental investments. Psychological Science 22: 203-208. https://doi.org/10.1177/ 0956797610397057

Evans, E.D. and Warren-Sohlberg. (1988). A pattern analysis of adolescent abusive behavior towards parents. Journal of Adolescent Research 3(2): 201-216. https://doi.org/10.1177/074355488832007

Feinberg, J. (1987). The Moral Limits of the Criminal Law: Volume 1: Harm To Others. Oxford: Oxford University Press. https://doi.org/10.1093/0195046641. 001.0001

Fineman, M. (2008). The vulnerable subject: Anchoring equality in the human condition. Yale Journal of Law and Feminism 20: 1-23.

Gheaus, A. (2015). Unfinished adults and defective children: On the nature and value of childhood. Journal of Ethics and Social Philosophy 9(1): 1-21.

(2011). Arguments for nonparental care for children. Social Theory and Practice 37(3): 483-509. https://doi.org/10.5840/soctheorpract201137328

Glenn and McLanahan (1981). Glenn, N. D., \& McLanahan, S. (1982). Children and marital happiness: A further specification of the relationship. Journal of Marriage and the Family 44: 63-72.

Goodin, R. (1985). Protecting the Vulnerable: A Reanalysis of Our Social Responsibilities. Chicago: University of Chicago Press.

Halpern, J. (2001). From Detached Concern to Empathy. Oxford: Oxford University Press. https://doi.org/10.1093/acprof:osobl/9780195111194.001.0001

Hannan, S. and Vernon, R. (2008). Parental rights: A role-based approach, Theory and Research in Education 6(2): 173-189. https://doi.org/10.1177/1477878 508091110 
Harriman, L. C. (1983). Personal and marital changes accompanying parenthood. Family Relations 32(3): 387-394. https://doi.org/10.2307/584616

Kabat-Zinn, J. (2003). Mindfulness-based interventions in context: Past, present, and future. Clinical Psychology 10(2): 144-156. https://doi.org/10.1093/ clipsy.bpg016

Kabat-Zinn, M. and Kabat-Zinn, J. (1997/2014). Everyday Blessings: The Inner Work of Mindful Parenting. New York: Hyperion Publishing/Hatchette Books.

Kittay, E. (1999). Love's Labour: Essays on Women, Equality and Dependency. New York: Routledge.

Lotz, M. (2014a). Parental values and children's vulnerability. In Mackenzie, C., Rogers, W. and Dodds, S. (Eds.), Vulnerability: New Essays in Ethics and Feminist Philosophy (pp. 242-265). Oxford: Oxford University Press.

(2014b). Adoptee vulnerability and post-adoptive parental obligation. In Baylis, F. and McLeod, C. (Eds.), Family-Making: Contemporary Ethical Challenges (pp. 198-221). Oxford: Oxford University Press. https://doi.org/10.1093/acprof:oso/9780199656066.003.0012

. (2016). Vulnerability and resilience: A critical nexus. Theoretical Medicine and Bioethics 37(1): 45-59. https://doi.org/10.1007/s11017-0169355-y

Macleod, C. (2017). Doctrinal vulnerability and the authority of children's voices. In Straehle, C. (Ed.), Vulnerability, Autonomy and Applied Ethics (pp. 171-184). New York: Routledge.

Marples, R. (2017). Parents' rights and the control of children's education. In Ahlberg, J. and Cholbi, M. (Eds.), Procreation, Parenthood, and Educational Rights: Ethical and Philosophical Issues (pp. 137-167). New York: Routledge.

McLanahan, S. and Adams, J. (1987). Parenthood and psychological well-being. Annual Review of Sociology 13: 237-257. https://doi.org/10.1146/annurev.so. 13.080187.001321

McTernan, E. (2015). Should fertility treatment be state funded? Journal of Applied Philosophy 32(3): 227-240. https://doi.org/10.1111/japp.12091

Miller, J.J., Fletcher, K., and Kabat-Zinn, J. (1995). Three-year follow-up and clinical implications of a mindfulness meditation-based stress reduction intervention in the treatment of anxiety disorders. General Hospital Psychiatry 17(3): 192200. https://doi.org/10.1016/0163-8343(95)00025-M

Millum, J. (2010). How do we acquire parental rights? Social Theory and Practice 36(1): 112-132. https://doi.org/10.5840/soctheorpract 20103615 2008. How do we acquire parental responsibilities? Social Theory and Practice 34(1): 71-93. https://doi.org/10.5840/soctheorpract20083414

Murray, T. H. (1996). The Worth of a Child. Berkeley and Los Angeles: University of California Press.

National Survey of Families and Households (NSFH). Available at http://www.ssc.wisc.edu/nsfh/ (Last accessed 20 March 2017).

Nelson, S.K., Kushlev, K., English, T., Dunn, E.W., and Lyubomirsky, S. (2013). In defense of parenthood: Children are associated with more joy than misery. Psychological Science 24(1): 3-10. https://doi.org/10.1177/0956797612447798

Newman, L. (2008). How parenthood experiences influence desire for more children in Australia: A qualitative study. Journal of Population Research 25(1): 1-27. https://doi.org/10.1007/BF03031938 
Nomaguchi, K. and Milkie, M. (2003). Costs and rewards of children: The effects of becoming a parent on adults' lives. Journal of Marriage and Family 65(2): 356374. https://doi.org/10.1111/j.1741-3737.2003.00356.x

Overall, C. (2012). Why Have Children? The Ethical Debate. Cambridge: MIT Press.

Parker, R. (1995). Torn in Two: The Experience of Maternal Ambivalence. London: Virago.

. (1994). Maternal ambivalence. Winnicott Studies 9: 3-17.

. (1997). The production and purposes of maternal ambivalence. In Hollway, W. and Featherstone, B., (Eds.), Mothering and Ambivalence (pp. 16-36). London: Routledge.

Piper, A. (1991). Impartiality, compassion, and modal imagination. Ethics 101(4): 726-757. https://doi.org/10.1086/293341

Powdthavee, N. (2009). Think having children will make you happy? The Psychologist 22: 308-311.

. (2008). Putting a price tag on friends, relatives, and neighbours: Using surveys of life satisfaction to value social relationships. The Journal of SocioEconomics 37: 1459-1480. https://doi.org/10.1016/j.socec.2007.04.004

Quiney, R. (2007). Confessions of the new capitalist mother: Twenty-first-century writing on motherhood as trauma. Women: A Cultural Review 18(1): 19-40. https://doi.org/10.1080/09574040701276704

Ramsay, M. (2017). Liberalism, parental rights, and moral education: Yet another reflection on Mozert v. Hawkins. In Ahlberg, J. and Cholbi M. (Eds.), Procreation, Parenthood, and Educational Rights: Ethical and Philosophical Issues (pp. 168-200). New York: Routledge.

Read, D.M.Y., Crockett, J., Mason, R. (2012). "It was a horrible shock": The experience of motherhood and family size preferences. Women's Studies International Forum 25: 12-21. https://doi.org/10.1016/j.wsif.2011.10.001

Rich, A. (1976). Of Woman Born: Motherhood as Experience and Institution. New York: Norton.

Robinson, P. W., Davidson, L. J., \& Drebot, M. E. (2004). Parent abuse on the rise: A historical review. American Association of Behavioral Social Science Online Journal 7: 58-67.

Robinson, M. D., \& Clore, G. L. (2002). Belief and feeling: Evidence for an accessibility model of emotional self-report. Psychological Bulletin 128: 934960. https://doi.org/10.1037/0033-2909.128.6.934

Romans, S. E., Poore, R. \& Martin, J. (2001), The perpetrators of domestic violence. Medical Journal of Australia 173: 484-488.

Ross, C. E., \& Huber, J. (1985). Hardship and depression. Journal of Health and Social Behavior 26: 312-327. https://doi.org/10.1037/0033-2909.128.6.934

Shelton, N. and Johnson, S. (2006). "I think motherhood for me was a bit like a double-edged sword": The narratives of older mothers. Journal of Community \& Applied Social Psychology 16: 316-330. https://doi.org/10.1002/casp.867

Stanca, L. (2012). Suffer the little children: Measuring the effects of parenthood on well-being worldwide. Journal of Economic Behavior \& Organization 81(3): 742-50. https://doi.org/10.1016/j.jebo.2010.12.019

Stevens, E.N., Bardeen, J.R., and Murdock, K.W. (2015). Parenting behaviours and anxiety in young adults. Journal of Individual Differences 36(3): 170-176. https://doi.org/10.1027/1614-0001/a000169 
Turner, B. S. (2006). Vulnerability and Human Rights. University Park, PA: Penn State University Press.

Umberson, D., \& Gove, W. R. (1989). Parenthood and psychological well-being: Theory, measurement, and stage in the family life course. Journal of Family Issues 10: 440-462. https://doi.org/10.1177/019251389010004002 